\title{
A heterogeneidade mostrada e marcada: vozes com o argumento de autoridade
}

\author{
Cleonice Men da Silva RAMOS (USP)
}

RESUMO: Ao considerar a delegação de vozes com o propósito de atribuir um poderfazer a sujeitos, falar em nome do narrador, que remete ao enunciador, este artigo objetiva mostrar como as vozes nos discursos citados, tomadas com o argumento de autoridade, tecem o texto/discurso, contribuindo na construção do éthos do enunciador.

PALAVRAS-CHAVE: heterogeneidade mostrada e marcada; discursos citados; argumento de autoridade; éthos; enunciador.

ABSTRACT: By considering that a narrator delegates voices to other subjects with the purpose of conferring them being-able-to do, to speak in his name, this paper aims at showing how the quoted speeches, taken as authority arguments, can contribute not only to the text/discourse production but also to the enunciator ethos revealing.

KEYWORDS: heterogeneity shown and marked; quoted speeches, authority argument; "ethos"; enunciator. 


\section{Preliminares}

Toma-se, para este artigo, o gênero textual constituinte reportagem de capa da revista EXAME, edição 734, de 21 de fevereiro de 2001, intitulada "O Futuro da Fábrica". A revista EXAME, da Editora Abril, é um veículo da mídia impressa, de circulação quinzenal, cuja temática diz respeito à esfera de negócios e economia.

\section{Conceitos}

A metodologia utilizada na análise é de linha francesa, de A.J. Greimas e seus estudiosos.

A reportagem de capa tomada para análise é considerada um recorte, a parte que remete ao todo, à totalidade das reportagens, ou ainda, conforme conceitos aplicados por Discini (cf. 2003: 31-35), o unus, que pressupõe o totus, a totalidade integral. A autora complementa (2003: 35): "Desse eixo, totus/unus desponta o efeito de individuação, base do estilo. Desse eixo desponta o ethos constituinte do efeito de sujeito de uma totalidade".

Observa-se que as teorias do éthos (de Maingueneau) e do estilo (de Discini) estão intimamente relacionadas. O éthos é entendido como um modo de ser e de se apresentar no mundo de um sujeito, de cuja imagem se depreendem um tom de voz, uma corporalidade e um caráter. Lembremos, assim, as palavras de Maingueneau (1997: 46): "Mas o tom, por si só, não recobre, em seu conjunto, o campo do ethos enunciativo. O tom está necessariamente associado a um caráter e a uma corporalidade". Esse autor (2002: 99) ainda complementa: "o ethos implica, com efeito, uma disciplina do corpo apreendido por intermédio de um comportamento global”.

O estilo, para Discini, é uma construção do discurso que remete a um efeito de sentido de sujeito. Esse efeito pode ser descrito ao reconstruir traços recorrentes e depreensíves da totalidade enunciada de um texto, que remete a uma individualidade, pois "o estilo é um conjunto de características da expressão e do conteúdo que criam um ethos" (Discini, 2003: 7).

\section{Análise}

Considera-se que vozes de outros sujeitos, delegadas por um $e u$, o narrador, podem ser instaladas com o propósito de atribuir a esses sujeitos um poder-fazer, falar em nome daquele que os dota de voz.

Como recorrência nas reportagens de capa da revista EXAME, o repórterjornalista, considerado narrador, que remete ao enunciador, delega a palavra a outro sujeito, instaurando uma segunda voz no texto, que é caracterizada como um discurso citado no discurso citante (cf. Maingueneau, 2002: 138). O narrador, eu, introduz a fala, dá a voz a um outro, o que marca a delegação de vozes no enunciado. $\mathrm{O}$ discurso citado, se for um discurso direto, "é um simulacro da enunciação construído por intermédio do discurso do narrador" (Fiorin, 2001: 72). 
Observa-se que esses discursos dispensam o travessão, no que divergem da prática comum às obras literárias. Vigora o uso de aspas, o que caracteriza, do mesmo modo, um discurso direto, uma heterogeneidade mostrada e marcada. $\mathrm{O}$ discurso citado, feito por meio de marcação aspeada, forma assim um terceiro nível da hierarquia enunciativa e opera uma debreagem de segundo grau. "O $e u$ que fala em discurso direto é dominado por um $e u$ narrador que, por sua vez, depende de um $e u$ pressuposto pelo enunciado", diz Fiorin (2001: 45).

Com efeito, os discursos citados são formados por diversas vozes que colaboram para constituir o discurso. O leitor, como co-enunciador do gênero revista empresarial, tem a expectativa reforçada: ele espera a delegação de vozes, como leitor normatizado pelo gênero.

Apresentamos, a seguir, alguns discursos citados juntamente com o citante, retirados da reportagem de capa da revista mencionada. Destaca-se o alto grau de iconização verbal dos antropônimos Helton Luís de Mello, Marcel Dedin e outros que, com nome, sobrenome e idade posposta, aumentam o efeito de realidade e da verdade "transparente", obedecendo à caracterização do contrato fiduciário entre enunciador e enunciatário de qualquer mídia.

"No meu time de trabalho, uns devem ajudar e complementar os outros" diz Helton Luís de Mello, 25 anos, soldador da linha do modelo A3, produzido pela Audi em São José dos Pinhais (EXAME, 21/02/2001, p. 44).

"A partir de então, estabelecemos um compromisso" diz José Loureiro Cardoso, diretor industrial da Eli Lilly no Brasil. "O compromisso de que aquelas determinações serão religiosamente seguidas" (EXAME, 21/02/2001, p. 45).

"Passei a semana inteira aprendendo como me vestir para entrar no setor de trabalho" diz Marcel Dedin, 28 anos, estudante do segundo ano de farmácia. "Foi importante porque lá dentro tudo tem de ser perfeito e eu sou responsável por isso". Todos os dias, antes de penetrar no asséptico e solitário mundo da cristalização estéril, um dos processos críticos da produção de antibióticos injetáveis, Dedin entra na intranet da Eli Lilly (EXAME, 21/02/2001, p. 45-46).

No exemplo que segue, dois ou até três discursos citados estão dispostos seguidamente para a tessitura do texto. O discurso citante, do narrador, intercala-se entre as vozes citadas.

"A coisa mais legal dessa empresa é que todo mundo procura fazer sempre melhor" diz Sandra Lia Dantas Barreto, 29 anos, uma das operadoras do setor de perfumes da Natura. "As coisas estão sempre mudando, mas isso não significa pressão ou sacrifício”. Enquanto Sandra comanda as máquinas e ajuda a organizar a produção, seus dois filhos, Caio, de 2 anos, e Lílian, de 7 meses, ficam no berçário da fábrica. Após o nascimento da filha, Sandra pensou em 
deixar o emprego, mas desistiu "A Natura faz parte da minha vida há muito tempo" (EXAME, 21/02/2001, p. 49).

Ressalte-se o tom da voz citada, a do empregado, harmônica em relação ao ambiente em que trabalha. A voz citante, do narrador, ratifica o mesmo tom de voz do discurso citado.

No caso específico do discurso abaixo transcrito, a voz citada foi posta logo depois do título do texto, ou seja, sem nenhum comentário anterior do narrador, o que remete a um alto grau de importância dessa voz. Temos então, logo após o título, o discurso citado iniciando o parágrafo:

[Título]: "A fábrica transformada em comunidade

"As pessoas querem sentir que são parte de algo maior. Elas têm necessidade de compartilhar idéias, problemas e objetivos" diz Marisa Caldas, 44 anos, gerente do Espaço Natura desde setembro do ano passado. Marisa é a prefeita da fábrica (EXAME, 21/02/2001, p. 46).

Essa voz faz apreciações, expressa pontos de vista em conformidade com o assunto discorrido na reportagem, o que imprime maior consistência discursiva e efeitos de veracidade, contribuindo, assim, para fortalecer a construção da competência do narrador.

Faz-se necessária ainda uma observação. Os discursos citados da reportagem de capa analisada apresentam uma especificidade: são colocados no texto sem ter antes um verbo ilocutório ou dicendi, cuja função seria alertar o enunciatário-leitor de que uma nova voz entraria no discurso. O verbo dicendi é, portanto, usado somente após a citação e no final dela. Vejamos dois exemplos de discursos citados com tal procedimento.

"A arquitetura é apenas um reflexo de conceitos e crenças corporativas que devem marcar o terceiro século da industrialização". "Queremos que este lugar rompa com a idéia tradicional de fábrica", diz Pedro Luiz Passos, sócio e presidente de operações da Natura" (itálico: grifo nosso), (EXAME, 21/02/2001, p. 41).

"Algumas das fábricas instaladas aqui na década de 90 iniciaram um círculo virtuoso", diz Paulo Apsan, presidente da filial brasileira da consultoria americana Arthur D. Little. "Elas estabelecem um novo padrão, que vem sendo copiado mundo afora" (itálico: grifo nosso), (EXAME, 21/02/2001, p. 41).

Esse procedimento é um recurso utilizado pelo narrador e objetiva a economia no tempo de leitura. Maingueneau (2002: 145) se posiciona a respeito desse recurso do narrador, que "[...] exibe sua preocupação de ir direto ao essencial, poupando o tempo precioso de um leitor provavelmente também muito ocupado". A referência ao tempo precioso de leitura tem pertinência quando se considera a imagem desse leitor como a de um sujeito com alto envolvimento nos negócios, caracterização, por definição, do 
sujeito moderno da área empresarial. Com efeito, esse indivíduo, por construir para si o simulacro de que vive conciliando as muitas horas de trabalho com as de lazer e as de dedicação à família, confirma-se como um apreciador da estratégia de economia de tempo nas leituras. Com tal recurso, temos delineada a construção do éthos do enunciador: direcionado e comprometido com o enunciatário-leitor.

Ratifica-se que, nos discursos citados da reportagem de EXAME, os sujeitos são mostrados e marcados pelo narrador que lhes delegou voz, ou seja, são identificados pelo nome e cargo social que ocupam, o que aumenta a ilusão de verdade referencial. As vozes desses sujeitos, ditas em discurso direto, contribuem "por conseguinte, para o efeito de verdade, tão caro ao discurso jornalístico" (Discini, 2005: 121). Essas vozes, portanto, são consideradas com o argumento de autoridade. Sobre isso, Discini (2005: 336-337) afirma que

O argumento de autoridade:

. refere-se à citação de pensamentos de autoridades no assunto estudado, para que se confirme o ponto de vista proposto pelo narrador;

. confirma o outro como o adjuvante, do nível narrativo; aquele que colabora para a construção da competência do próprio narrador, no sentido de viabilizar o poder e saber defender um ponto de vista;

. contribui para o efeito de tom criterioso da voz.

Citar uma autoridade em sua área de atuação legitima-a como adjuvante e, portanto, "fiador" do ponto de vista anunciado. Assim, o outro citado, com ares de autoridade, visa a "ajudar" a validar o discurso citante, ou seja, tornar mais verossímil o que se afirma na reportagem. Esses sujeitos são, portanto, previamente eleitos porque considerados em suas especialidades e habilidades dentro do universo corporativo empresarial, isto é, são selecionados por uma suposta competência e pelo prestígio que tais habilidades lhes conferem, especialmente a partir da posição hierárquica corporativa e/ou social que detêm. Ao apontar essa suposta competência, de que é dotado um sujeito no exercício de seu cargo ou função dentro do universo empresarial, em uma esfera social, portanto, trazemos os conceitos do discurso competente de Chaui $(1989: 7,11)$ :

O discurso competente é o discurso instituído. É aquele no qual a linguagem sofre uma restrição que poderia ser assim resumida: não é qualquer um que pode dizer a qualquer outro qualquer coisa em qualquer lugar e em qualquer circunstância (p. 7).

O que é o discurso competente enquanto discurso do conhecimento? Sabemos que é o discurso do especialista, proferido de um ponto determinado da hierarquia organizacional. Sabemos também que haverá tantos discursos competentes quantos lugares hierárquicos autorizados a falar e a transmitir ordens aos degraus inferiores e aos demais pontos da hierarquia que lhe forem paritários (p. 11). 
Nessa perspectiva, corrobora-se o sentido de que sujeitos considerados em suas competências esperadas estão num espaço discursivo determinado habilitados a falar. As vozes citadas servem, dessa maneira, como reforço ao discurso instituído que, por sua vez, detêm o argumento de autoridade no assunto proferido com o mesmo olhar ético proposto pela enunciação. A citação, em discurso citado, considerado com o argumento de autoridade, é estratégia argumentativa do enunciador, por ele usada, como manipulador-destinador, para manipular o leitor. O destinatário é levado a crer, propósito, aliás, do discurso jornalístico, pautado pela informação com ideais de certeza e veracidade dos fatos e não pela dúvida. Para Greimas e Courtès (1989: 45-46), certeza

é a demonstração do termo positivo da categoria modal epistêmica, cuja definição sintáxica seria o crer-ser. Diferentemente da evidência, a certeza pressupõe o exercício do fazer interpretativo, do qual ela é uma das conseqüências possíveis.

Pelas mostras de interação entre sujeitos, não há brechas para a dúvida. Todas essas vozes partilham a mesma voz socializada pela mídia que trata de negócios. Há, portanto, um entendimento mútuo, que determina uma só formação discursiva. Essas vozes são concordantes e mantêm com a voz citante uma relação de parceria ética, visto pertencerem a sujeitos engajados eticamente em uma temática singular, já que são previamente eleitos a discursar, a proferir suas falas.

Cabe aqui, contudo, uma nova observação. Segundo Maingueneau (2002: 138), "Quando o enunciador cita no discurso direto a fala de alguém, não se coloca como responsável por essa fala, nem como sendo o ponto de referência de sua ancoragem na situação de enunciação [...]". Assim, a delegação de vozes, marcada pelo elemento tipográfico aspas promove a ruptura sintática na delegação de vozes no texto. Essas duas vozes, a do discurso citante e a do discurso citado, mantêm as fronteiras de quem diz no enunciado. Mas todas as vozes convergem para o mesmo éthos, sustentado pelos valores comprometidos com as mesmas aspirações.

\section{Breve conclusão}

Observamos que, no gênero textual reportagem de capa, os discursos citados no discurso citante mantêm um diálogo contratual, com vozes que se compõem harmoniosamente e, desse modo, completam a unidade temática discursiva concordante. Essas vozes, enfim, amalgamam-se em um só discurso. O resultado é um efeito de completude, placidez e autenticidade de uma unidade institucional discursiva com valores e crenças estabelecidos, que delineiam a construção de um éthos moderante e autocentrado do enunciador.

Os ideais de certeza por que se pauta o enunciador da reportagem se consolidam por meio das citações em discurso direto das vozes com o argumento de autoridade. Assim se constrói o convencimento do enunciatário-leitor na tessitura do texto e do discurso. Para isso serve o argumento de autoridade. 
A heterogeneidade mostrada e marcada, no gênero textual reportagem de capa, contribui para a compactação do corpo do ator da enunciação: aquele que conta, ao informar e expor, com um público eleito para tecer seu discurso. Um discurso é assim constituído e recebido pelo enunciatário-leitor que, lembremos, é a imagem especular do sujeito da enunciação, este que detém a voz do discurso. Enunciador e coenunciadores (os leitores) tecem e completam, portanto, o mundo feito discurso.

\section{REFERÊNCIAS BIBLIOGRÁFICAS}

CHAUI, Marilena. Cultura e democracia - o discurso competente e outras falas. 9. ed. São Paulo: Cortez, 1989.

DISCINI, Norma. O estilo nos textos. São Paulo: Contexto, 2003. . Comunicação nos textos. São Paulo: Contexto, 2005.

FIORIN, José Luiz. As astúcias da enunciação: as categorias de pessoa, espaço e tempo. 2. ed. São Paulo: Ática, 2001.

GREIMAS, Algirdas Julien e COURTÈS, Joseph. Dicionário de semiótica. Trad. Alceu Dias Lima et alii. São Paulo: Cultrix, 1989.

MAINGUENEAU, Dominique. Novas Tendências em análise do discurso. 3. ed. São Paulo: Ed. da UNICAMP, 1997. . Análise de textos de comunicação. 2. ed. São Paulo: Cortez, 2002.

\section{Como citar este artigo:}

RAMOS, Cleonice Men da Silva. A heterogeneidade mostrada e marcada: vozes com o argumento de autoridade. Estudos Semióticos, Número 2, São Paulo, 2006. Disponível em <www.fflch.usp.br/dl/semiotica/es>. Acesso em "dia/mês/ano". 